\title{
PENERAPAN ALGORITMA APRIORI DALAM MENENTUKAN POLA PEMBELIAN KONSUMEN DI KAFE HIDDEN TOAST AND FLOAT
}

\author{
Ridwan Rismanto ${ }^{1}$, Lucki Darmawan ${ }^{2}$, Arief Prasetyo ${ }^{3}$ \\ Jurusan Teknologi Informasi, Program Studi Teknik Informatika, Politeknik Negeri Malang \\ ${ }^{1}$ r.rismanto@gmail.com, ${ }^{2}$ luckidarma@gmail.com, ${ }^{3}$ tiyok_pras@yahoo.com
}

\begin{abstract}
Abstrak
Advances in Information Technology encourage culinary entrepreneurs to innovate, one of them with a computerized system, online-based sales and some interesting features that can increase consumer interest and increase sales become the most frequently used innovation today. Cafe "Hidden Toast and Float" is a cafe in Kediri. To increase sales from the cafe, a system is needed that can facilitate the owner in recording sales and increase the number of sales by providing automatic menu recommendations to customers. Based on the problem, in this thesis will be made a recording system and website-based sales system accompanied by application of a priori algorithm to know the pattern of purchasing from customers as well as automatic menu recommendation from system to customer. The test results from this thesis are two website-based systems with admin systems used to process existing data on the database and customer website used for online purchases, as well as the application of a priori algorithm with the results of sample data and real data sampling resulting in recommendation of menu combination most often purchased based on all transaction data of Dark Choco Jam and Cappucino with 15\% support value and $45 \%$ confidence value.
\end{abstract}

Kata Kunci : Kafe Hidden Toast and Float, Website, Algoritma Apriori

\section{Pendahuluan}

\subsection{Latar Belakang}

Hirarki kebutuhan manusia terbagi menjadi beberapa kategori yaitu kebutuhan fisiologis atau dasar, kebutuhan untuk dicintai dan disayangi, kebutuhan untuk dihargai dan kebutuhan untuk aktualisasi diri. Pada tingkat kebutuhan dasar atau kebutuhan fisiologis adalah kebutuhan yang sangat berkaitan erat dengan kebutuhan tubuh manusia.[7] Contohnya adalah kebutuhan pangan, pangan merupakan salah satu dari sekian kebutuhan primer. Maka pemenuhan terhadap pangan menjadi hal yang mutlak bagi manusia agar menjaga kelangsungan hidupnya. Setelah kebutuhan primer terpenuhi baru akan muncul kebutuhan - kebutuhan lainnya seperti kebutuhan bersosialisasi, percaya diri dan aktualisasi diri yang dirata - rata merupakan 3 teratas kebutuhan manusia.

Kafe "Hidden Toast And Float" merupakan sebuah kafe di Kota Kediri yang berdiri sejak tahun 2014. Kafe ini terletak di Jalan Mojoroto Gang 2 No $12 \mathrm{~F}$ Kota Kediri. Pada kafe ini lebih banyak menyediakan menu-menu berupa makanan ringan seperti roti, kentang goreng, rice bowl dan sebagainya. Dengan harga yang ekonomis sasaran kafe ini yaitu lebih kepada mahasiswa maupun kalangan pelajar, dikarenakan letak kafe yang dekat dengan universitas dan sekolah. Dengan adanya fasilitas take away, pelanggan dapat membeli tanpa harus datang ke tempat. Banyaknya pilihan menu semakin memanjakan pelanggan untuk berulang membeli dari kafe ini, tetapi akan lebih baik jika terdapat sebuah sistem yang dapat memberikan sebuah rekomendasi menu kepada pelanggan dan juga sistem untuk melayani pembelian secara online pada lingkup Kediri kota, sehingga akan memberikan keuntungan baik kepada pihak kafe maupun pihak pelanggan

Penelitian ini dilakukan untuk Mengetahui bagaimana konsep e-commerce diterapkan dalam sistem jual-beli dan menganalisa algoritma Apriori untuk memanfaatkan data transaksi yang tersimpan pada database web e-commerce Kafe Hidden Toast ad Float guna mengetahui jumlah dan kombinasi item kategori menu yang banyak terjual secara bersamaan sebagai bahan pertimbangan dalam membuat kebijakan dan strategi bisnis melalui analisa dengan algoritma Apriori serta mengetahui cara perancangan desain web e-commerce Kafe Hidden Toast And Float. 


\subsection{Rumusan Masalah}

Berdasarkan latar belakang diatas, maka rumusan masalah adalah sebagai berikut :

a. Bagaimana cara penerapan Algoritma Apriori dalam menentukan pola pembelian konsumen pada Kafe Hidden Toast And Float?

b. Data apa sajakah yang akan diolah oleh Algoritma Apriori sehingga didapatkannya sebuah pola pembelian konsumen?

\subsection{Tujuan}

Adapun tujuan yang ingin dicapai dari penelitian yang dilakukan yaitu :

a. Untuk mengetahui pola pembelian konsumen pada Kafe Hidden Toast And Float pada sisi pemilik kafe.

b. Untuk memberikan rekomendasi menu pada konsumen.

\subsection{Batasan Masalah}

a. Sistem ini digunakan sebagai sarana rekomendasi menu untuk pelanggan.

b. Pengambilan data dilakukan di Kafe Hidden Toast And Float Kediri.

c. Sistem ini hanya mencakup wilayah Kediri Kota.

d. Data yang diambil adalah data transaksi selama 1 tahun terakhir.

\section{Landasan Teori}

\subsection{CodeIgniter}

CodeIgniter adalah sebuah framework php yang bersifat open source dan menggunakan metode MVC (Model, View, Controller). CodeIgniter bersifat free alias tidak berbayar. Framework CodeIgniter di buat dengan tujuan sama seperti framework lainnya, yaitu untuk mempermudah developer atau programmer dalam membangun sebuah aplikasi berbasis webiste tanpa harus membuat dari awal[8]. Pada Sistem yang saya kembangkan ini, Penerapan framework codeigniter digunakan untuk halaman admin dan user.

\subsection{Data Mining}

Data mining adalah proses yang menggunakan teknik statistik, matematika, kecerdasan buatan, dan machine learning untuk mengekstrasi dan mengedintifikasi informasi yang bermanfaat dan pengetahuan yang terkait dari berbagai database besar.[2] Data mining bukanlah suatu bidang yang sama sekali baru. Salah satu kesulitan untuk mendefinisikan data mining adalah kenyataan bahwa data mining mewarisi banyak aspek dan teknik dari bidang-bidang ilmu yang sudah mapan terlebih dahulu.

Data mining dibagi menjadi beberapa kelompok berdasarkan tugas yang dapat dilakukan, yaitu :

$\begin{array}{ll}\text { a. } & \text { Deskripsi } \\ \text { b. } & \text { Estimasi } \\ \text { c. } & \text { Klasifikasi } \\ \text { d. } & \text { Prediksi } \\ \text { e. } & \text { Pengklusteran } \\ \text { f. } & \text { Asosiasi }\end{array}$

\subsection{Algoritma Apriori}

Apriori adalah algoritma yang digunakan dalam melakukan pencarian frequent itemset untuk mendapatkan aturan asosiasi. Sesuai dengan namanya, algortima ini menggunakan prior knowledge mengenai frequent itemset properties yang telah diketahui sebelumnya untuk memproses informasi selanjutnya. Apriori menggunakan pendekatan secara iterative yang disebut juga sebagai level-wish search dimana k-itemset digunakan untuk mencari $(\mathrm{k}+1)$ itemset. Pertama-tama dicari set dari frequent 1itemset, set ini dinotasikan sebagai L1. L1 yaitu large itemset pertama yang digunakan untuk menemukan L2, kemudian set dari frequent 2-itemset digunakan untuk menemukan L3, dan seterusnya sampai tidak ada lagi frequent $\mathrm{k}$-itemset yang dapat ditemukan. Large itemset adalah itemset yang sering terjadi atau itemset-itemset yang sudah melewati batas minimum support.

Algoritma Apriori sendiri termasuk ke dalam data mining asosiasi atau Association Rule mining yang teknik data mining untuk menemukan aturan asosiatif antara suatu kombinasi item.[4] Contoh aturan asosiatif dari analisis pembelian di suatu pasar swalayan adalah dapat diketahuinya berapa besar kemungkinan seorang pelanggan membeli roti bersama dengan susu. Dengan pengetahuan tersebut, pemilik pasar swalayan dapat mengatur penempatan barangnya atau merancang kampanye pemasaran dengan memakai kupon diskon untuk kombinasi barang tertentu, aturan yang menyatakan asosiasi antara beberapa atribut sering disebut affinity analiysis atau Market Basket Analysis.

Kelebihan dari algoritma apriori ini adalah lebih sederhana dan dapat menangani data yang besar. Sedangkan algoritma lainnya memiliki kelemahan dalam penggunaan memori saat jumlah data besar, tentunya berpengaruh terhadap banyaknya item yang 
diproses serta mudah di pahami struktur kerja dan implementasinya.[4]

Apriori memiliki kelemahan karena harus melakukan scan database setiap kali iterasi, sehingga waktu yang diperlukan bertambah dengan makin banyak terasi yang telah ditentukan.[4]

\section{Metodologi}

\subsection{Tahapan Penelitian}

Metode pengembangan yang digunakan dalam "Penerapan Algoritma Apriori dalam Menentukan Pola Pembelian Konsumen di Kafe Hidden Toast and Float" adalah Model Prototyping, model Prototyping sendiri adalah proses iteratif dalam pengembangan sistem di mana kebutuhan diubah ke dalam sistem yang berkerja (working system) yang secara terus menerus diperbaiki melalui kerjasama antara pengguna dan analis.[1]

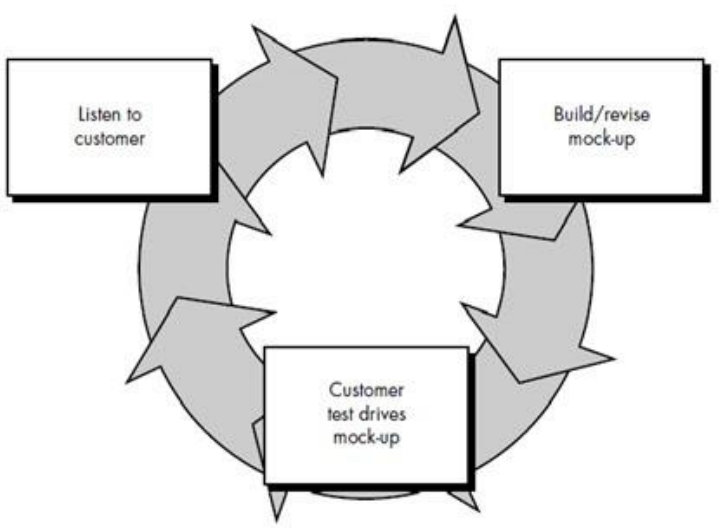

Gambar 2.1 Metode Prototyping

Pada algoritma Apriori menentukan kandidat yang mungkin muncul dengan cara memperhatikan minimum support dan minimum confidence. Support adalah nilai pengunjung atau persentase kombinasi sebuah item dalam database.

Rumus support adalah sebagai berikut :

$$
\begin{gathered}
\text { Support }(A, B)=P(A \cap B) \\
\text { Support } A, B)= \\
\frac{\sum \text { Transaksi mengandung } A \text { dan } B}{\sum \text { Total Transaksi }} \times 100 \% \\
\text { Rumus Support }[12]
\end{gathered}
$$

Sedangkan confidence adalah nilai kepercayaan yaitu kuatnya hubungan antar item dalam sebuah Apriori. Confidence dapat dicari setelah pola frekuensi munculnya sebuah item ditemukan. Berikut rumus confidence :

$$
\text { Confidence }=P(B \mid A)=
$$

\section{$\Sigma$ Transaksi mengandung $A$ dan $B$ \\ Transaksi Mengandung $A$ \\ Rumus Confidence[12]}

Konsep Apriori :

Itemset adalah sekumpulan item item dalam sebuah keranjang (Support). K-itemset adalah itemset yang berisi $\mathrm{K}$ item, misalnya beras,telur,minyak adalah 3-itemset (Dinotasikan sebagai K-itemset).

Frequent support adalah $k$-itemset yang dimiliki oleh support dimana frequent $\mathrm{k}$-itemset yang dimiliki diatas minimum support atau memenuhi minimum support (dinotasikan sebagai Fi).

Kandidat itemset adalah frequent itemset yang dikombinasikan dari k-itemset sebelumnya (dinotasikan sebagi $\mathrm{Ci}$ ).

\subsection{Gambaran Sistem}

Berdasarkan hasil wawancara, diskusi dan survei langsung ke kafe Hidden Toast And Float, owner dari kafe setuju untuk dibuatkan sebuah sistem pemesanan yang berbasis online, baik pemesanan menu makanan atau miniman dan pemesanan tempat untuk acara ulang tahun, serta menerapkan hasil dari algoritma apriori ke dalam sistem pelanggan yang merekomendasikan menu makanan disaat pelanggan melihat detail dari salah satu menu. Gambaran desain sistem dapat dilihat dari Gambar 4.1.

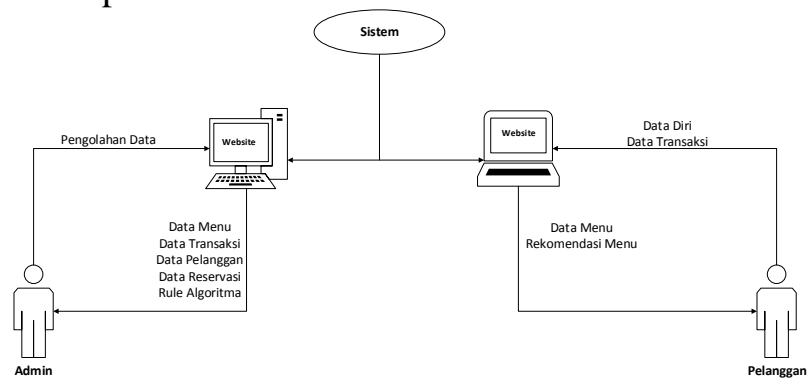

Gambar 2.2 Gambaran Sistem

\section{Hasil dan Pembahasan}

\subsection{Analisa dan Perancangan}

Pada tahap ini sistem pertama kali akan dikembangankan dalam tahap implementasi kecil, penulis menggunakan excel untuk mengolah data kecil terlebih dahulu dalam penerapan algoritma apriori. Langkah analisa apriori sebagai berikut :

$$
\text { a. Data Transaksi }
$$

Tabel 4.1 Data Transaksi Permenu

\begin{tabular}{|l|l|l|}
\hline No & Nama Menu & Jumlah \\
\hline 1 & Mayo Beef & 3 \\
\hline 2 & Vanilla Cheese & 0 \\
\hline
\end{tabular}




\section{$\underline{\text { Penerapan Algoritma Apriori Dalam Menentukan Pola Pembelian Konsumen }}$}

\begin{tabular}{|c|c|c|}
\hline 3 & Sweet Strawberry Jam & 10 \\
\hline 4 & Dark Choco Jam & 20 \\
\hline 5 & Banana Choco Corn & 0 \\
\hline 6 & Ricebowl Original & 7 \\
\hline 7 & Ricebowl Hot Chili & 4 \\
\hline 8 & Ricebowl Barbeque & 9 \\
\hline 9 & Ricebowl Teriyaki & 3 \\
\hline 10 & Ricebowl Blackpepper & 3 \\
\hline 11 & French Fries & 18 \\
\hline 12 & Big Sosis & 3 \\
\hline 13 & Ice in Cup & 0 \\
\hline 14 & Burger & 5 \\
\hline 15 & Crispy Nugget & 1 \\
\hline 16 & Fried Banana Jam & 0 \\
\hline 17 & Ice Tea & 6 \\
\hline 18 & Lemon Tea & 3 \\
\hline 19 & Саррисіпо & 23 \\
\hline 20 & Strawberry Squash & 3 \\
\hline 21 & Lemon Squash & 0 \\
\hline 22 & Green Mojito & 9 \\
\hline 23 & Vanilla Float & 1 \\
\hline 24 & Choco Float & 12 \\
\hline 25 & Strawberry Float & 0 \\
\hline 26 & Cocacola Float & 1 \\
\hline 27 & Fanta Float & 0 \\
\hline 28 & Hot Choco & 1 \\
\hline 29 & Hot Tea & 0 \\
\hline 30 & Hot Cappucino & 2 \\
\hline 31 & Hot Coffe & 3 \\
\hline 32 & Hot Creamy Coffe & 0 \\
\hline 33 & Hot Lemon Tea & 0 \\
\hline 34 & Choco Gingger & 0 \\
\hline 35 & Gingger Milk & 0 \\
\hline
\end{tabular}

Kemudian menentukan apakah data transaksi tersebut memenuhi minimum support, yaitu minimum support yang ditentukan $20 \%$.

Tabel 4.2 Nilai Support Transaksi Per Menu

\begin{tabular}{|c|c|c|}
\hline No & Nama Menu & $\begin{array}{c}\text { Nilai } \\
\text { Support }\end{array}$ \\
\hline 1 & Mayo Beef & 8 \\
\hline 2 & Vanilla Cheese & 0 \\
\hline
\end{tabular}

\begin{tabular}{|c|c|c|}
\hline 3 & $\begin{array}{l}\text { Sweet Strawberry } \\
\text { Jam }\end{array}$ & 26 \\
\hline 4 & Dark Choco Jam & 53 \\
\hline 5 & $\begin{array}{l}\text { Banana Choco } \\
\text { Corn }\end{array}$ & 0 \\
\hline 6 & Ricebowl Original & 18 \\
\hline 7 & Ricebowl Hot Chili & 11 \\
\hline 8 & Ricebowl Barbeque & 24 \\
\hline 9 & Ricebowl Teriyaki & 8 \\
\hline 10 & $\begin{array}{r}\text { Ricebowl } \\
\text { Blackpepper }\end{array}$ & 8 \\
\hline 11 & French Fries & 47 \\
\hline 12 & Big Sosis & 8 \\
\hline 13 & Ice in Cup & 0 \\
\hline 14 & Burger & 13 \\
\hline 15 & Crispy Nugget & 3 \\
\hline 16 & Fried Banana Jam & 0 \\
\hline 17 & Ice Tea & 16 \\
\hline 18 & Lemon Tea & 8 \\
\hline 19 & Саррисіпо & 61 \\
\hline 20 & Strawberry Squash & 8 \\
\hline 21 & Lemon Squash & 0 \\
\hline 22 & Green Mojito & 24 \\
\hline 23 & Vanilla Float & 3 \\
\hline 24 & Choco Float & 32 \\
\hline 25 & Strawberry Float & 0 \\
\hline 26 & Cocacola Float & 3 \\
\hline 27 & Fanta Float & 0 \\
\hline 28 & Hot Choco & 3 \\
\hline 29 & Hot Tea & 0 \\
\hline 30 & Hot Cappucino & 5 \\
\hline 31 & Hot Coffe & 8 \\
\hline 32 & Hot Creamy Coffe & 0 \\
\hline 33 & Hot Lemon Tea & 0 \\
\hline 34 & Choco Gingger & 0 \\
\hline 35 & Gingger Milk & 0 \\
\hline
\end{tabular}

Tahap selanjutnya dengan mencari kombinasi itemset yang memenuhi support, dengan rumus yang telah ditentukan.

Tabel 4.3 Transaksi yang Memenuhi Support

\begin{tabular}{|c|c|c|c|c|}
\hline $\mathbf{N}$ & Menu & Menu & Ju & $\begin{array}{c}\text { Suppor } \\
\mathbf{0}\end{array}$ \\
\hline
\end{tabular}


Jurnal Teknologi Informatika dan Terapan Vol. 04, No 02, Juli - Desember 2017 ISSN: 235-838X

\begin{tabular}{|r|c|c|c|c|}
\hline 1 & $\begin{array}{c}\text { Dark } \\
\text { Choco } \\
\text { Jam }\end{array}$ & $\begin{array}{c}\text { Cappu } \\
\text { cino }\end{array}$ & 14 & 37 \\
\hline 2 & $\begin{array}{c}\text { Riceb } \\
\text { owl } \\
\text { Barbeque }\end{array}$ & $\begin{array}{c}\text { Cappu } \\
\text { cino }\end{array}$ & 8 & 21 \\
\hline 3 & $\begin{array}{c}\text { Frenc } \\
\text { Fries }\end{array}$ & $\begin{array}{c}\text { Cappu } \\
\text { cino }\end{array}$ & 13 & 34 \\
\hline 4 & $\begin{array}{c}\text { Cappu } \\
\text { cino }\end{array}$ & $\begin{array}{c}\text { Dark } \\
\text { Choco } \\
\text { Jam }\end{array}$ & 14 & 37 \\
\hline
\end{tabular}

Setelah mendapatkan kombinasi dua menu yang memenuhi support, kemudian langkah selanjutnya mencari kombinasi dua menu yang memenuhi nilai minimum confidence yaitu $60 \%$.

Tabel 4.4 Transaksi yang Memenuhi Confidence

\begin{tabular}{|c|c|c|c|c|}
\hline $\mathbf{0} \mathbf{N}$ & 1 Menu & 2 Menu & h Jumla & $\begin{array}{l}\begin{array}{l}\text { Co } \\
\text { nfiden } \\
\text { ce }\end{array} \\
\end{array}$ \\
\hline 1 & $\begin{array}{l}\text { Dark } \\
\text { Choco } \\
\text { Jam }\end{array}$ & $\begin{array}{l}\text { Cарри } \\
\text { cino }\end{array}$ & 14 & 70 \\
\hline 2 & $\begin{array}{l}\quad \text { Ricebo } \\
\text { wl } \\
\text { Barbeque }\end{array}$ & $\begin{array}{l}\text { Cарри } \\
\text { cino }\end{array}$ & 8 & 89 \\
\hline 3 & $\begin{array}{l}\text { French } \\
\text { Fries }\end{array}$ & $\begin{array}{l}\text { Cappu } \\
\text { cino }\end{array}$ & 13 & 72 \\
\hline 4 & $\begin{array}{l}\text { Cарpu } \\
\text { cino }\end{array}$ & $\begin{array}{l}\text { Dark } \\
\text { Choco } \\
\text { Jam }\end{array}$ & 14 & 61 \\
\hline
\end{tabular}

Dari hasil kombinasi dua menu yang memenuhi nilai minimum support dan minimum confidence, didapatkan 4 kombinasi menu yang menjadi rute dari algoritma apriori. Yaitu kombinasi menu Dark Choco Jam dan Cappucino, Ricebowl Barbeque dan Cappucino, French Fries dan Cappucino, Cappucino dan Dark Choco Jam. Sementara untuk hasil perkalian Support X Confidence dapat dilihat pada tabel 4.5

Tabel 4.5 Nilai Support X Confidence

\begin{tabular}{|c|c|c|c|}
\hline No & Menu 1 & Menu 2 & $\begin{array}{l}\text { Support } \\
\text { Confidence }\end{array}$ \\
\hline 1 & $\begin{array}{c}\text { Dark } \\
\text { Choco Jam }\end{array}$ & ${ }_{o} \quad$ Cappucin & 0,26 \\
\hline 2 & $\begin{array}{c}\text { Ricebowl } \\
\text { Barbeque }\end{array}$ & ${ }_{o}$ Cappucin & 0,19 \\
\hline 3 & $\begin{array}{c}\text { French } \\
\text { Fries }\end{array}$ & ${ }_{o}$ Cappucin & 0,25 \\
\hline 4 & $o^{\text {Cappucin }}$ & $\begin{array}{c}\text { Dark } \\
\text { Choco Jam }\end{array}$ & 0,22 \\
\hline
\end{tabular}

Kombinasi dari dua menu yang memiliki nilai support X confidence terbesar adalah Dark Choco Jam dan Cappucino dengan nilai 0,26.

\section{Implementasi}

\subsection{Tampilan Rule Algoritma Apriori Pada Website Admin}

Penerapan Algoritma Apriori pada sisi amin menampilkan hasil frekuensi pembelian tertinggi yang telah dilakukan oleh pelanggan.

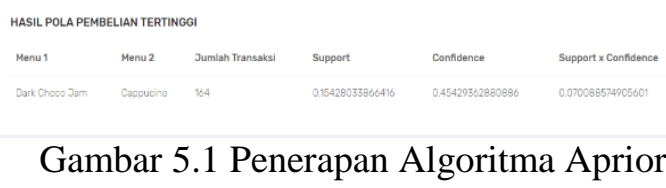

\subsection{Rekomendasi Menu}

Hasil penerapan Algoritma Apriori pada sisi pelanggan yaitu memberikan rekomendasi menu otomatis kepada pelanggan, seperti yang ditunjukkan pada gambar 5.2 berikut ini :

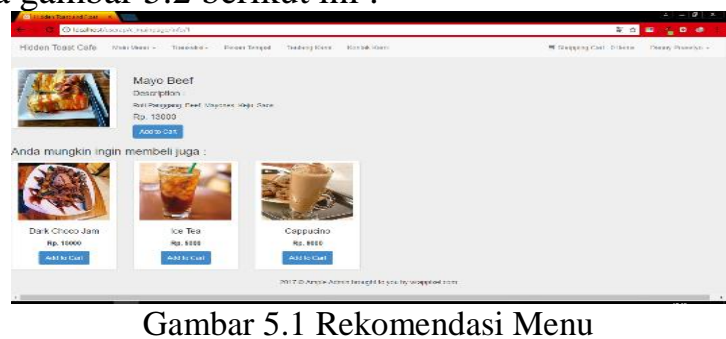

\section{Ujicoba}

6.1. Pengujian
6.1.1
Hasil
Pengujian
Algoritma
Rekomendasi Menu

Tabel 6.1 Hasil Pengujian

\begin{tabular}{|c|c|c|}
\hline No & Menu & \multicolumn{1}{|c|}{ Rekomendasi } \\
\hline 1 & Mayo Beef & - Dark Choco \\
& & $\begin{array}{c}\text { Jam } \\
\text { - Ice Tea } \\
\text { - Cappucino }\end{array}$ \\
\hline 2 & & - Cappucino \\
\hline 3 & Vanilla Cheese & - Dark Choco \\
& Strawberry Jam & Jam \\
& & - Ice Tea \\
& & - Cappucino \\
\hline 4 & Dark Choco & - Ice Tea \\
& Jam & - Lemon Tea \\
& & - Cappucino \\
& & - Green Mojito \\
& & - Mayo Beef \\
\hline 5 & Ricebowl Tea \\
& Original & - Cappucino \\
\hline 6 & Ricebowl Hot & - Cappucino \\
& Chili & \\
\hline
\end{tabular}




\begin{tabular}{|c|c|c|}
\hline 7 & $\begin{array}{c}\text { Ricebowl } \\
\text { Blackpepper }\end{array}$ & $\begin{array}{l}\text { - Ice Tea } \\
\text { - Cappucino }\end{array}$ \\
\hline 8 & French Fries & - Cappucino \\
\hline 9 & Crispy Nugget & - Cappucino \\
\hline 10 & Ice Tea & - Cappucino \\
\hline 11 & Cappucino & - Choco Float \\
\hline
\end{tabular}

Hasil pengujian menggunakan data real sebanyak 1065 data transaksi menghasilkan beberapa rekomendasi kombinasi menu seperti yang terlihat pada gambar 6.1, dengan kombinasi menu yang paling sering dibeli yaitu Dark Choco Jam disertai pembelian Cappucino dengan nilai support $15 \%$ dan nilai confidence $45 \%$.

\section{Kesimpulan}

\subsection{Kesimpulan}

Beberapa kesimpulan yang dapat diambil dari hasil penelitian ini :

a. Hasil Penerapan Algoritma Apriori pada sisi Admin, dapat menampilkan kombinasi menu yang sering dibeli oleh pelanggan.

b. Penerapan Algoritma Apriori pada sisi Pelanggan dapat menghasilkan rekomendasi menu yang secara otomatis diberikan oleh sistem.

c. Nilai minimum support menunjukkan bahwa semakin tinggi nilai, semakin sering menu dibeli oleh pelanggan.

d. Semakin tinggi nilai minimum confidence, semakin kuat hubungan antara dua menu yang dibeli.

e. Algoritma Apriori cocok digunakan untuk menemukan kombinasi pembelian menu tertinggi dari pelanggan dengan hasil dari data sampel dan data real menghasilkan kombinasi menu yang sama yaitu Dark Choco Jam dan Cappucino dengan nilai support $15 \%$ dan nilai confidence $45 \%$.

\subsection{Saran}

a. Penerapan Algoritma Apriori agar dapat dimaksimalkan untuk promo produk, sehingga menambah minat pelanggan.

\section{Daftar Pustaka}

[1] Al Fatta, Hanif. 2007. "Analisis \& Perancanan Sistem Informasi untuk Keunggulan Bersaing Perusahaan \& Organisasi Modern". Andi Offset. Yogyakarta.

[2] Kusrini dan Luthfi, E. T., 2009, Algoritma Data Mining, Andi Offset, Yogyakarta

[3 ]Robi Yanto, Riri Khoiriah, "Implementasi Data Mining dengan Metode Algoritma Apriori dalam Menentukan
Pola Pembelian Obat", Citec Journal, Vol 2, No. 2, Februari 2015-April 2015.

[4] Safar Riduan Pasaribu, "Sistem Pendukung Keputusan Analisa Pola Penjualan Barang dengan Algoritma Apriori (Studi Kasus: Lucky Swalayan)," Pelita Informatika Budi Darma, vol. 6, no. 2, pp. 119 - 123, 2014.

[5] Susanto, Azhar. 2004. "Sistem Informasi Manajemen Konsep dan Pengembangannya". Bandung: Lingga Jati

[6] Bansal, Ubay. 2016. "Sistem Informasi dalam Bisnis Global". http://www.ubaybansal.tk/2016/04/sistem-informasidalam-bisnis-global.html Diakses Tanggal 21 Juni 2016

[7] GoPangan Lokal. 2013. "Peran Strategis Industri Kuliner Bagi Pertumbuhan Ekonomi" http://gopanganlokal.miti.or.id/index.php/peranstrategis-industri-kuliner-bagi-pertumbuhan-ekonomi. [Tanggal 14 Desember 2016]

[8] Hadi, Diki Alfarabi. 2016. "CodeIgniter Part 1: Pengertian dan Cara Menggunakan CodeIgniter". http://www.malasngoding.com/pengertian-dan-caramenggunakan-codeigniter [Tanggal 2 Januari 2017]

[9] Hia, Budieli. 2009. "Teori Abraham Maslow Tentang Tingkat Kebutuhan https://budishia.wordpress.com/2009/12/29/teorikebutuhan-menurut-maslow/. [Tanggal 14 Desember 2016]

[10] Putra, Michael. 2016. "Pengertian dan Manfaat Website". https://www.sayanda.com/pengertian-dan-manfaatwebsite/. [Tanggal 2 Januari 2017]

[11] Restofocus. 2015. "Pengertian dan Unsur Restoran". http://www.restofocus.com/2015/01/pengertian-danunsur-restoran.html. [Tanggal 14 Desember 2016]

[12] Ruci Tita. 2016. "Pengertian Algoritma Apriori". http://www.ilmuskripsi.com/2016/05/algoritmaapriori.html [Tanggal 2 Januari 2017] 